\title{
Evaluating the factor structure of the General Self-Efficacy Scale
}

\author{
Petrus Nel and Adré Boshoff
}

\begin{abstract}
Although the Sherer General Self-Efficacy Scale has often been used in clinical, personality, and organisational research, one of the major issues surrounding this instrument is that of an appropriate factor structure. In an endeavour to address the criticism levelled against this scale, this article draws on a study aimed at investigating the psychometric properties of the Sherer General Self-Efficacy Scale with respect to both its factor structure and estimates of reliability. A quantitative, cross-sectional research design with convenience sampling was used. A total of 295 aspiring chartered accountants who had sat one of their compulsory examinations completed the Sherer General Self-Efficacy Scale. Both the minimum average partial test and parallel analysis suggested that a unidimensional structure be investigated. Confirmatory factor analysis was used to compare two competing measurement models representing a threedimensional factor structure and a unidimensional factor structure. Both models exhibited fairly similar levels of fit. To break this impasse, the Schmid-Leiman solution provided evidence that the Sherer General Self-Efficacy Scale consisted of a strong general factor which explained $76 \%$ of the variance. This study therefore concluded that general self-efficacy, as measured by the Sherer General Self-Efficacy Scale, may be treated as a unidimensional construct.
\end{abstract}

Bandura (1986) states that 'people may judge themselves efficacious only in certain domains of functioning or across a wide range of activities and situations' (p. 396). It follows that self-efficacy may vary in generality. Sherer et al. (1982) are of the opinion that contextspecific self-efficacy may be adapted to investigate a more global or general efficacy. Concurrently, Chen, Gully, and Eden (2001) suggest that general self-efficacy (GSE) can be distinguished from specific self-efficacy. The latter is a task-specific belief, while GSE is a trait-like, generalised competence belief. GSE can therefore be viewed as an individual's ability to cope, perform, and be successful within novel situations (Judge \& Bono, 2001). More specifically, GSE is defined as 'a judgement of how well one can perform across a variety of situations' (Judge, Erez, Bono, \& Thoreson, 2002, p. 96).

Although self-efficacy may be domain specific, Bosscher and Smit (1998) argue that numerous experiences of failure and success in various domains of an individual's life may also be important, requiring general beliefs about self-efficacy. GSE is therefore a motivational state as it involves the individual's beliefs regarding his or her abilities to 
perform and succeed at tasks across different situations (Kanfer \& Heggestad, 1997), whereas self-efficacy emphasises a task-specific belief (Chen, Gully, \& Eden, 2004).

In essence, specific self-efficacy is a situation- or context-specific competence belief, while GSE seems to be a situation-independent competence belief (Scherbaum, Cohen-Charash, \& Kern, 2006). Specific self-efficacy can be regarded as a motivational state, while GSE can be regarded as a motivational trait (Chen et al., 2001). It should therefore be noted that GSE is neither a substitute nor a replacement for specific self-efficacy. Thus, GSE may predict additional variance when the generalised performance of an individual is of interest to researchers.

\section{Some correlates of GSE}

In the introduction, the similarities and differences between GSE and specific self-efficacy were highlighted. However, GSE is also related to other personality constructs. Bono and Judge (2003) found a relationship between GSE and the following three personality constructs: self-esteem $(r=.85)$, emotional stability $(r=.62)$, and locus of control $(r=$ .56). Due to a lack of available theory, the discussion that follows will focus only on the relationship between GSE and two of those constructs, namely, self-esteem and locus of control (Chen et al., 2004; Judge \& Bono, 2001; Locke, McClear, \& Knight, 1996).

According to Chen et al. (2004), both GSE and self-esteem have the following in common: both constructs are part of general self-evaluations, and both encompass cognitive, affective, and motivational elements. In addition, GSE is related to self-esteem in that both emphasise the self- appraisal of an individual's future success or failure (Locke et al., 1996).

However, GSE and self-esteem also differ from each other. First, GSE emphasises a motivational belief regarding an individual's capabilities to perform a task, while selfesteem seems to emphasise an emotional evaluation regarding the self. Second, from a motivational perspective, GSE seems to be related to the achievement/approach motivational process, while self-esteem seems to be related to the anxiety/avoidance affective process. GSE can be viewed as a motivational trait (i.e., an individual's belief that he or she is capable to perform and succeed in tasks across different domains), whereas self-esteem can be viewed as an emotional trait (i.e., an individual's general feelings related to value and self-worth; Chen et al., 2004). In short, GSE indicates the degree to which individuals 'judge their capabilities', whereas self-esteem reflects how individuals 'feel about themselves' (Chen et al., 2004, p. 389). Self-esteem thus has a self-worth component that is lacking in GSE (Locke et al., 1996).

GSE also seems to be theoretically related to locus of control (Judge \& Bono, 2001, p. 97). Individuals who view themselves as capable in general also believe that they have control over their lives (i.e., internal locus of control). In addition, Judge and Bono (2001) provide examples of items that overlap between a measure of locus of control and GSE. 


\section{Measuring GSE}

South African psychologists and industrial psychologists in particular are being challenged to research those factors that influence optimal human functioning (Coetzee \& Viviers, 2007). More specifically, future researchers are encouraged to investigate the role of several psychological strengths (such as self-efficacy and GSE; Coetzee \& Cilliers, 2001; Rothmann \& Cilliers, 2007) and their impact on health and well-being. In order to do so, researchers need to have access to valid and reliable instruments that can be used to carry out future research.

According to Chen et al. (2001), the Sherer General Self-Efficacy Scale (SGSES; Sherer et al., 1982) is the most widely used measure in clinical, personality, and organisational research. More specifically, it has been used or cited by more than 200 published studies. However, there seems to be conflicting evidence related to the most appropriate factor structure associated with the SGSES. Sherer et al. (1982) obtained a single factor, while others have identified multiple factors (Chen et al., 2001; Woodruff \& Cashman, 1993). Contrary to the proposed unidimensional structure, Woodruff and Cashman (1993) found a three-factor structure, consisting of initiative, effort, and persistence, using the 17 -item questionnaire with a 5-point Likert scale. Two additional studies found support for this three-dimensional structure (Bosscher \& Smit, 1998; Chen \& Gully, 1997). For example, Bosscher and Smit (1998) developed a 12-item version based on the three-dimensional structure after the removal of poor loading items. The three subscales of the 12-item instrument produced the following alphas: (a).64, (b) .63, and (c) .64 .

Given the conflicting findings obtained by previous research, the aim of this study is to investigate the psychometric properties of the SGSES with respect to both its factor structure and estimates of reliability.

\section{Method}

\section{Research design}

In order to execute the research, this study employed a cross-sectional design with a survey as data-collection technique.

\section{Participants}

A convenience sample of 295 aspiring chartered accountants who had sat one of their mandatory examinations participated in the study. Given that approximately 3000 candidates were invited to participate, the current response rate was close to $10 \%$. The sample characteristics and size are not close to the ideal for the type of analysis envisaged by this study, but it is acceptable and usable (Gagne \& Hancock, 2006). There were more women $(n=161 ; 55 \%)$ than men, while $36 \%$ of the sample consisted of participants from designated groups (i.e., African, coloured, and Indian students; $n=107$ ). The ages of participants ranged between 22 and 49 years (mean $=27$; standard deviation $[S D]=5$ ). The relationship status of the majority of the respondents was single $(n=213)$. 


\section{Instrument}

The 17-item version of the SGSES, with a 5-point Likert scale, was used. This scale consists of three sub-dimensions, namely, initiative, effort, and persistence. The initiative subdimension was measured using five items (e.g., 'I avoid trying to learn new things when they look too difficult for me'), while the sub-dimensions of effort (e.g., 'When I decide to do something, I go right to work on it') and persistence (e.g., 'I do not seem capable of dealing with most problems that come up in my life') were measured using eight and four items, respectively.

\section{Procedure}

Permission was obtained from the relevant professional body to approach a group of aspiring chartered accountants to participate in the study. An electronic letter of invitation was sent to those who had completed the compulsory professional exam. The letter contained a link to an electronic survey. Research participants were informed that they were under no obligation to participate in this study. They were also informed that their anonymity would be assured. Finally, the participants were assured that no individual results would be published. Only aggregated data for the total group would be reported and discussed.

\section{Ethical considerations}

Ethical clearance for the investigation was granted by the research committees of the Department of Industrial Psychology and the Faculty of Economic and Management Sciences at Stellenbosch University.

\section{Data analysis}

Exploratory factor analysis (EFA) using principal axis factoring was employed to investigate the underlying structure of the latent variable. In order to determine the number of factors to be extracted, both parallel analysis (PA; Horn, 1965) and the minimum average partial test (MAP; Velicer, 1976) were used.

To evaluate the factor structure obtained through EFA, this study employed confirmatory factor analysis (CFA). In doing so, the study followed the suggestion by Van Prooijen and Van Der Kloot (2001) that 'if CFA cannot confirm results of EFA on the same data, one cannot expect that CFA will confirm results of EFA in a different sample or population' (p. 780). The data were treated as continuous, and by analysing the covariance matrix, the data were assessed for normality (Jackson, Gillaspy, \& Purc-Stephenson, 2009). A test of multivariate normality was used to determine the skewness of data to be used during CFA (Jöreskog \& Sörbom, 2006). On the basis of the test of multivariate, the data were deemed negatively skewed. The latter required the use of the robust maximum likelihood method of estimation.

All analyses related to the CFA were conducted using LISREL 8.80 (Jöreskog \& Sörbom, 2006). Several fit indices were used, including the Satorra-Bentler scaled chi-square, root mean square error of approximation (RMSEA), comparative fit index (CFI), and the goodness-of-fit index (GFI). Values close to .95 for GFI and CFI are considered indicative of a 
good model fit. It is suggested that values close to .06 are indicative of an acceptable fit for RMSEA (Hu \& Bentler, 1999). In addition, Akaike's Information Criterion (AIC) can be used when comparing competing models, with lower values indicating the better fitting model (Byrne, 2006).

To estimate the reliability associated with the dimensions of the SGSES, Cronbach's alpha (a) was employed. Reliability estimates that are .7 and higher are indicative of good reliability. However, estimates as low as. 6 may be acceptable when conducting exploratory research (Hair, Black, Babin, Anderson, \& Tatham, 2006).

Table I. Factor loadings and communalities for the unidimensional structure of the SGSES.

\begin{tabular}{lll}
\hline Item & Factor I & Communality \\
\hline 1 & .574 & .329 \\
2 & .408 & .167 \\
3 & .531 & .282 \\
4 & .575 & .330 \\
5 & .515 & .266 \\
6 & .549 & .301 \\
7 & .578 & .334 \\
8 & .393 & .155 \\
9 & .423 & .179 \\
10 & .543 & .295 \\
11 & .514 & .264 \\
12 & .605 & .366 \\
13 & .531 & .282 \\
14 & .485 & .235 \\
15 & .354 & .126 \\
16 & .688 & .473 \\
17 & .584 & .341 \\
\hline
\end{tabular}

SGSES: Sherer General Self-Efficacy Scale.

Bartlett's statistic $=1314.5(\mathrm{df}=136 ; p<.001)$.

Kaiser-Meyer-Olkin (KMO) test $=.88713$.

\section{Results}

Table 1 provides evidence of the factorisability of the correlation matrix. The Kaiser-MeyerOlkin (KMO) value is above .6 and the $p$-value is smaller than .05 for Bartlett's test of sphericity. In addition, all the factor loadings are significant. These 17 items produced an acceptable level of reliability $(\alpha=.873)$ and explained $32 \%$ of the total variance.

The results obtained from the PA are reported in Table 2. From this table, it is evident that there is only a single eigenvalue from the dataset (5.42112) that is bigger than the eigenvalue (95th percentile) from the random dataset (1.53210). The results of the MAP in Table 3 indicate that the smallest average partial is .01084. This value is associated with the first dimension. Hence, based on the results of both PA and MAP, a unidimensional structure can be investigated by means of EFA.

Table 4 provides information on the approximate fit indices calculated using LISREL 8.80. The significant $p$-values associated with the Satorra-Bentler scaled chi-square point to a lack of model fit. In contrast, most of the indices indicate an acceptable model fit (CFI, RMSEA, 
and standardised root mean square residual [SRMR]), while others point to a mediocre fit (GFI). When comparing the two competing models, it seems that both conceptualisations are equally valid.

To break this impasse, the Schmid-Leiman solution (Revelle, 2014) was employed to determine whether the SGSES measures a strong general factor. From Table 5, it is clear the majority of the 17 items have higher factor loadings on the general factor than on their respective subscales. The general factor explains $76 \%$ of the variance. It can therefore be concluded that items of the SGSES measure a single dimension.

To allow for meaningful comparisons, this study conducted a CFA using the same 12 items as suggested by Bosscher and Smit (1998). The results are depicted in Table 5. Those researchers found evidence of a model with an acceptable fit when looking at the SRMR (.010).

Table 2. Parallel analysis results.

\begin{tabular}{llll}
\hline Variable & $\begin{array}{l}\text { Real-data } \\
\text { eigenvalues }\end{array}$ & $\begin{array}{l}\text { Mean of random } \\
\text { eigenvalues }\end{array}$ & $\begin{array}{l}\text { 95th percentile of } \\
\text { random eigenvalues }\end{array}$ \\
\hline 1 & 5.42112 & 1.43772 & 1.53210 \\
2 & 1.31131 & 1.34745 & 1.41675 \\
3 & 1.23106 & 1.27984 & 1.33126 \\
4 & 1.07924 & 1.22174 & 1.27305 \\
5 & 0.89391 & 1.16807 & 1.20974 \\
6 & 0.85050 & 1.11712 & 1.15470 \\
7 & 0.76191 & 1.06959 & 1.10846 \\
8 & 0.69956 & 1.02626 & 1.05875 \\
9 & 0.66993 & 0.98314 & 1.01876 \\
10 & 0.63994 & 0.94230 & 0.97711 \\
11 & 0.60942 & 0.90211 & 0.93933 \\
12 & 0.57209 & 0.85977 & 0.89427 \\
13 & 0.53631 & 0.82006 & 0.85415 \\
14 & 0.48067 & 0.77805 & 0.81492 \\
15 & 0.46933 & 0.73352 & 0.77376 \\
16 & 0.40410 & 0.68562 & 0.72742 \\
17 & 0.36960 & 0.62765 & 0.67631 \\
\hline
\end{tabular}

Table 3. Minimum average partial test results.

\begin{tabular}{lc}
\hline Dimensions & Average partial \\
\hline 1 & .01084 \\
2 & .01995 \\
3 & .04021 \\
4 & .10044 \\
5 & .47227 \\
6 & .99999 \\
\hline
\end{tabular}

However, their model also points to a lack of fit when considering the CFI (.830). In comparison, the results obtained in this study point to a model with acceptable levels of fit when both the SRMR and CFI are taken into consideration, although the significant $p$-value associated with the Satorra-Bentler scaled chi-square points to a lack of model fit. It is also 
clear that the goodness-of-fit statistics obtained by this study are better than those reported by Bosscher and Smit (1998) (Table 6). The standardised factor loadings and errors for the various measurement models are reported in Tables 7 and 8. It is evident that this information supports the factor loadings obtained through EFA (see Table 3). Furthermore, it is noteworthy that Items 2 and 15 have the lowest loadings, resulting in their having the largest error. The latter is observed in the low communalities reported for these two items in Table 3.

Descriptive statistics associated with the 17 items are reported in Table 9. Both the initiative ( $\alpha=.74)$ and effort $(\alpha=.73)$ dimensions have acceptable reliabilities. However, the persistence dimension has a lower reliability $(\alpha=.59)$.

Table 4. Summary of goodness-of-fit statistics of one-factor solution and three-factor solution of the SGSES.

\begin{tabular}{lll}
\hline & $\begin{array}{l}\text { Three-factor } \\
\text { solution }\end{array}$ & $\begin{array}{l}\text { One-factor } \\
\text { solution }\end{array}$ \\
\hline S-B $\chi^{2}$ & 198.248 & 207.189 \\
$(p<.001)$ & $(p<.001)$ \\
df & 116 & 119 \\
RMSEA & .049 & .050 \\
SRMR & $(.037 ; .061)$ & $(.039 ; .062)$ \\
CFI & .055 & .057 \\
GFI & .969 & .967 \\
AIC & .915 & .911 \\
\hline
\end{tabular}

SGSES: Sherer General Self-Efficacy Scale; S-B $\chi^{2}$ : Satorra-Bentler scaled chi-square; df: degrees of freedom; RMSEA: root mean square error of approximation; SRMR: standardised root mean square residual; CFl: comparative fit index; GFl: goodness-of-fit index; AIC: Akaike's information criterion.

Table 5. Schmid-Leiman factor loadings greater than .2.

\begin{tabular}{|c|c|c|c|c|}
\hline Item & General factor & Factor I & Factor 2 & Factor 3 \\
\hline Item I & .45 & & & \\
\hline Item 2 & .32 & & .30 & .41 \\
\hline Item 3 & .52 & & & -.33 \\
\hline Item 4 & .58 & & & \\
\hline Item 5 & .50 & & & \\
\hline Item 6 & .51 & & & .35 \\
\hline Item 7 & .58 & & & \\
\hline Item 8 & .33 & & .42 & \\
\hline Item 9 & .31 & & .64 & \\
\hline Item 10 & .53 & & & \\
\hline Item II & .50 & & & \\
\hline Item 12 & .61 & & & \\
\hline Item 13 & .52 & & & \\
\hline Item 14 & .47 & & & \\
\hline Item 15 & .33 & & & \\
\hline Item 16 & .69 & & & \\
\hline Item 17 & .60 & & & \\
\hline
\end{tabular}

\section{Discussion}

The primary aim of this study was to investigate the appropriateness of both the unidimensional and three-dimensional factor structures associated with the SGSES. The 
discussion will first compare the findings obtained by this study with other research that also used this scale. Second, the psychometric properties of two other well-known measures of the GSE will be compared with those obtained by this study. Limitations and recommendations for future research are also discussed.

Table 6. Summary of goodness-of-fit statistics of the revised three-factor solution suggested by Bosscher and Smit (1998).

\begin{tabular}{lll}
\hline & $\begin{array}{l}\text { Three-factor solution (revised) } \\
\text { Bosscher and Smit (1998) }\end{array}$ & $\begin{array}{l}\text { Three-factor solution (revised) } \\
\text { Current Sample }\end{array}$ \\
\hline ML $\chi^{2}$ & 843.51 & - \\
S-B $\chi^{2}$ & - & 93.418 \\
& & $(p<.001)$ \\
df & 54 & 51 \\
RMSEA & - & .053 \\
& - & $(.036 ; .070)$ \\
SRMR & .010 & .050 \\
CFI & .830 & .969 \\
GFI & - & .945 \\
\hline
\end{tabular}

ML $\chi^{2}$ : maximum likelihood chi-square; S-B $\chi^{2}=$ Satorra-Bentler scaled chi-square; df: degrees of freedom; RMSEA: root mean square error of approximation; SRMR: standardised root mean square residual; GFl: goodness-of-fit index; CFl: comparative fit index.

Table 7. Standardised factor loadings and errors: unidimensional factor structure of the SGSES.

\begin{tabular}{lll}
\hline Item & Factor loading & Error \\
\hline Item I & .468 & .78 I \\
Item 2 & .365 & .867 \\
Item 3 & .504 & .746 \\
Item 4 & .571 & .675 \\
Item 5 & .521 & .728 \\
Item 6 & .530 & .719 \\
Item 7 & .583 & .660 \\
Item 8 & .378 & .857 \\
Item 9 & .391 & .847 \\
Item I0 & .517 & .733 \\
Item II & .477 & .772 \\
Item I2 & .572 & .673 \\
Item I3 & .541 & .707 \\
Item I4 & .486 & .764 \\
Item I5 & .339 & .885 \\
Item I6 & .688 & .526 \\
Item I7 & .590 & .652 \\
\hline
\end{tabular}

SGSES: Sherer General Self-Efficacy Scale.

To determine the appropriateness of a three-dimensional factor structure, as suggested by Bosscher and Smit (1998), Imam (2007), and Woodruff and Cashman (1993), this study employed CFA to determine the goodness-of-fit of such a model. It should be noted that all three studies reported moderate to high factor loadings. Items that had lower loadings were predominantly associated with negatively worded items. All three dimensions had negatively worded items. However, all the loadings were deemed to be significant and added to the interpretation of the various factors. A similar pattern was observed in the results reported by this study. However, these lower loadings did not negatively impact the overall goodness-offit. 
Table 8. Standardised factor loadings and errors: three-dimensional factor structure of the SGSES.

\begin{tabular}{|c|c|c|c|c|}
\hline \multirow[t]{2}{*}{ Item } & \multicolumn{3}{|c|}{ Factor loading } & \multirow[t]{2}{*}{ Error } \\
\hline & Initiative & Effort & Persistence & \\
\hline Item I & & .488 & & .762 \\
\hline Item 2 & & .386 & & .851 \\
\hline Item 3 & & .517 & & .732 \\
\hline Item 4 & & .578 & & .666 \\
\hline Item 5 & & .536 & & .712 \\
\hline Item 6 & .535 & & & .714 \\
\hline Item 7 & .598 & & & .642 \\
\hline Item 8 & & .396 & & .844 \\
\hline Item 9 & & .411 & & .831 \\
\hline Item 10 & .525 & & & .724 \\
\hline Item II & & & .533 & .715 \\
\hline Item 12 & .587 & & & .655 \\
\hline Item 13 & & .545 & & .702 \\
\hline Item 14 & & & .527 & .722 \\
\hline Item 15 & & & .351 & .877 \\
\hline Item 16 & .691 & & & .522 \\
\hline Item 17 & & & .658 & .568 \\
\hline
\end{tabular}

SGSES: Sherer General Self-Efficacy Scale.

Table 9. Descriptive statistics for the items and dimensions of the SGSES.

\begin{tabular}{|c|c|c|c|c|}
\hline Item/dimension & Minimum & Maximum & Mean & $S D$ \\
\hline Item I & 2 & 5 & 4.15 & 0.717 \\
\hline Item 2 & I & 5 & 3.28 & 1.323 \\
\hline Item 3 & I & 5 & 4.43 & 0.742 \\
\hline Item 4 & 2 & 5 & 4.24 & 0.840 \\
\hline Item 5 & I & 5 & 4.34 & 0.893 \\
\hline Item 6 & I & 5 & 3.64 & 1.193 \\
\hline Item 7 & I & 5 & 4.39 & 0.831 \\
\hline Item 8 & I & 5 & 3.80 & 1.166 \\
\hline Item 9 & I & 5 & 3.81 & 0.992 \\
\hline Item 10 & I & 5 & 4.16 & 0.938 \\
\hline Item II & I & 5 & 3.84 & 0.960 \\
\hline Item 12 & I & 5 & 4.23 & 0.946 \\
\hline Item 13 & I & 5 & 4.07 & 1.016 \\
\hline Item 14 & I & 5 & 3.65 & 1.216 \\
\hline Item 15 & I & 5 & 4.27 & 0.929 \\
\hline Item 16 & I & 5 & 4.48 & 0.815 \\
\hline Item 17 & 2 & 5 & 4.43 & 0.810 \\
\hline Initiative & 9 & 26 & 20.90 & 3.25 \\
\hline Effort & 16 & 41 & 32.10 & 4.60 \\
\hline Persistence & 8 & 21 & 16.18 & 2.66 \\
\hline
\end{tabular}

SGSES: Sherer General Self-Efficacy Scale; SD: standard deviation.

When comparing the results obtained by Bosscher and Smit (1998), who used a revised version of the SGSES, this study provided an improved fit (see Tables 4 and 5). Imam (2007) also used the SGSES and obtained a three-dimensional factor structure using EFA. A Cronbach's alpha of .85 for the total scale was reported. Unfortunately, no goodness-of-fit statistics or reliability estimates (for any of the three sub-dimensions) were reported. In a non-clinical Spanish sample with a 12-item version of the SGSES, support was found for a model representing three correlated factors with one higher order factor (Herrero et al., 
2014). The goodness-of-fit associated with this model was as follows: RMSEA $=.036$ and CFI $=.976$. The following reliability estimates for each of the three dimensions were found: initiative ( $\alpha=.64$ ), effort ( $\alpha=.63$ ), and persistence ( $\alpha=.64$; Herrero et al., 2014). The total scale obtained a Cronbach's alpha of .89. The goodness-of-fit of the three-factor model is fairly similar to the fit reported by Herrero et al. (2014) (RMSEA $=.049$ and CFI $=.969)$. The reliability estimates obtained in this study for both the initiative $(\alpha=.74)$ and effort $(\alpha=.73)$ dimensions are higher than those reported by Herrero et al. (2014). In contrast, Cronbach's alpha for the persistence dimension $(\alpha=.59)$ is slightly lower than that reported by Herrero et al. (2014). One possible reason for these differences may be the fact that the SGSES was translated into Spanish, which could have made it easier for the respondents to answer the 12 questions, consequently leading to higher reliabilities and better goodness-of-fit. Given that this study used the original English version of the SGSES, it may be possible that some of the respondents did not answer the questions in their mother tongue. In addition, by using only 12 items, the Spanish study may have benefitted from testing a less complex measurement model since there were fewer parameters to be estimated, resulting in a better fitting model.

EFA suggested a unidimensional structure associated with the SGSES. These findings concur with those of Sherer et al. (1982), who also obtained a single factor. Scherbaum et al. (2006) also found that the SGSES was unidimensional in nature based on the results of modified PA. They concluded that the 17 -item scale was reliable $(\alpha=.88)$. This may lend support to the fact that GSE has mainly been conceptualised as a unidimensional construct (Eden, 1988; Gardner \& Pierce, 1998; Judge, Locke, \& Durham, 1997). Scholz, Dona, Sud, and Schwarzer (2002) tested the assumption that the factor structure associated with the General Perceived Self-Efficacy Scale is unidimensional. Support for this factor structure was found, as evidenced by various goodness-of-fit statistics (GFI $=.98, \mathrm{RMR}=.033$, and RMSEA $=.05$ ). The items included in this unidimensional factor structure had an acceptable level of reliability ( $\alpha=.86$; Scholz et al., 2002, pp. 246-247). In addition, Chen et al. (2001) found acceptable psychometric properties associated with their New General-SelfEfficacy Scale - which is also unidimensional in nature. More specifically, the eight-item scale was deemed to be reliable $(\alpha=.85)$. Although Chen et al. (2004) reported goodnessof-fit statistics, a separate model associated with their instrument was not fitted - they combined their model with an instrument that measures self-esteem.

This study also found acceptable goodness-of-fit supporting a unidimensional factor structure $(\mathrm{GFI}=.91 \mathrm{CFI}=.97$, and RMSEA $=.05)$. These results are fairly similar when compared to the General Perceived Self-Efficacy Scale, except that a higher value was reported by Scholz et al. (2002, pp. 246-247) for the GFI (.98). In this study, a Cronbach's alpha of .85 was obtained for the total scale, whereas values of .86 and .85 were obtained by Scholz et al. (2002) and Chen et al. (2001), respectively. In short, when comparing the psychometric properties of the General Perceived Self-Efficacy Scale and the New General Self-Efficacy Scale with the results obtained by this study, which employed the SGSES, it seems that these three scales were comparable in terms of their reliabilities and goodnessof-fit. 
In support of the unidimensional structure of the SGSES, the Schmid-Leiman solution suggested that the 17 items of this instrument measure a strong general factor (i.e., GES) with very little evidence of the three subscales. The general factor accounted for $76 \%$ of the variance.

\section{Conclusion}

In summary, the results obtained by this study seem to suggest that the unidimensional structure is a more valid representation than the three-dimensional structure, given that both the MAP test and the Schmid-Leiman solution pointed to a unidimensional solution. Given the unidimensional nature of the SGSES, researchers and practitioners are therefore in a better position to interpret individuals' result as indicative of their beliefs about their abilities to perform efficaciously in a wide range of behaviours. Individuals with high levels of GSE will not only be in a better position to master skills required to complete specific tasks, by they may also have a general sense of mastery (Speier \& Frese, 1997). This will include their beliefs about their ability to cope with stressful situations in novel situations (Capri, Ozkendir, Ozkurt, \& Karakus, 2012). Such beliefs may indirectly influence their goal intentions and implementation intentions (e.g., action plans to implement goals). Finally, these GSE beliefs may also impact the positive perception regarding the possible outcomes of their behaviour (Luszczynska, Scholz, \& Schwarzer, 2005). Hence, the SGSES seems to cover a range of behavioural implications of self-efficacy (Sherer et al., 1982), providing useful information about GSE with scores on the SGSES enabling practitioners and researchers to use this instrument as part of an individual assessment (Scherbaum et al., 2006).

One concern highlighted in this study is the low reliability obtained for the persistence dimension. This dimension consists of four items, with Item 15 having the lowest factor loading. The removal of Item 15 does, however, not make much of a difference in the revised coefficient alpha $(\alpha=.581)$. It is therefore suggested that future researchers investigate the possibility of adding additional items (behavioural indicators) that provide a better reflection of the persistence dimension of the SGSES.

Although this study provides some insight into the structure of the SGSES, there are some suggestions to improve future investigations. First, it is advisable to investigate the factorial invariance of the SGSES in different South African sub-samples. This will enable researchers to determine whether culture or language influences respondents' perceived GSE. Second, more advanced statistical techniques, such as the Rasch analysis, should be used to supplement the results obtained in this study. The Rasch model may be very useful to investigate other measurement properties of the SGSES, such as item parameters, category thresholds, and measurement invariance (Bond \& Fox, 2007).

\section{Funding}

This research received no specific grant from any funding agency in the public, commercial, or not-for-profit sectors. 


\section{References}

Bandura, A. (1986). Social foundations of thought and action. Englewood Cliffs, NJ: Prentice Hall.

Bond, T. G., \& Fox, C. M. (2007). Applying the Rasch model: Fundamental measurement in the human sciences (2nd ed.). Mahwah, NJ: Lawrence Erlbaum.

Bono, J. E., \& Judge, T. A. (2003). Core self-evaluations: A review of the trait and its role in job satisfaction and job performance. European Journal of Personality, 17, S5-S18.

Bosscher, R. J., \& Smit, J. H. (1998). Confirmatory factor analysis of the general self-efficacy scale. Behavior Research \& Therapy, 36, 339-343.

Byrne, B. M. (2006). Structural equation modeling with EQS: Basic concepts, applications and programming (2nd ed.). Mahwah, NJ: Lawrence Erlbaum.

Capri, B., Ozkendir, O. M., Ozkurt, B., \& Karakus, F. (2012). General self-efficacy beliefs, life satisfaction and burnout of university students. Procedia, Social and Behavioral Sciences, 47, 968-973.

Chen, G., \& Gully, S. (1997, August). Specific self-efficacy, general self-efficacy, and selfesteem: Are they distinguishable constructs? Paper presented at the annual meeting of the Academy of Management, Boston, MA.

Chen, G., Gully, S. M., \& Eden, D. (2001). Validation of a new General Self-Efficacy Scale. Organizational Research Methods, 4, 62-83.

Chen, G., Gully, S. M., \& Eden, D. (2004). General self-efficacy and self-esteem: Toward theoretical and empirical distinction between correlated self-evaluations. Journal of Organizational Behavior, 25, 375-395.

Coetzee, S., \& Cilliers, F. V. N. (2001). Psychofortology: Explaining coping behaviour in organisations. The Industrial-Organisational Psychologist, 38, 62-68.

Coetzee, S., \& Viviers, R. (2007). An overview of research on Positive Psychology in South Africa. South African Journal of Psychology, 37, 470-490.

Eden, D. (1988). Pygmalion, goal setting, and expectancy: Compatible ways to raise productivity. Academy of Management Review, 13, 639-652.

Gagne, P., \& Hancock, G. R. (2006). Measurement model quality, sample size, and solution propriety in confirmatory factor models. Multivariate Behavioral Research, $41,65-83$.

Gardner, D. G., \& Pierce, J. L. (1998). Self-esteem and self-efficacy within the organizational context. Group \& Organization Management, 23, 48-70.

Hair, J. F., Black, B., Babin, B., Anderson, R. E., \& Tatham, R. L. (2006). Multivariate data analysis (6th ed.). Upper Saddle River, NJ: Prentice Hall.

Herrero, R., Espinoza, M., Molinari, G., Etchemendy, E., Garcia-Palacios, A., Botella, C., \& Banos, R. M. (2014).

Psychometric properties of the General Self Efficacy-12 Scale in Spanish: General and clinical population samples. Comprehensive Psychiatry. Retrieved from http://dx.doi.org/10.1016/j.comppsych.2014.05.015

Horn, J. L. (1965). A rationale and test for the number of factors in factor analysis. Psychometrika, 30, 179-185.

Hu, L., \& Bentler, P. M. (1999). Cutoff criteria for fit indexes in covariance structure analysis: Conventional criteria versus new alternatives. Structural Equation Modeling, 6, 1-55. 
Imam, S. S. (2007, May). Sherer et al. general self-efficacy scale: Dimensionality, internal consistency, and temporal stability. Proceedings of the Redesigning Pedagogy: Culture, Knowledge and Understanding Conference, Singapore.

Jackson, D. L., Gillaspy, J. A., \& Purc-Stephenson, R. (2009). Reporting practices in confirmatory factor analysis: An overview and some recommendations. Psychological Methods, 14, 6-23.

Jöreskog, K. G., \& Sörbom, D. (2006). LISREL 8.80 for Windows [Computer Software]. Lincolnwood, IL: Scientific Software International, Inc.

Judge, T. A., \& Bono, J. E. (2001). A rose by any other name: Are neuroticism, self-esteem, locus of control, and generalized self-efficacy indicators of a common construct? In B. W. Roberts \& R. T. Hogan (Eds.), Personality and psychology in the workplace (pp. 93-118). Washington, DC: American Psychological Association.

Judge, T. A., Erez, A., Bono, J. E., \& Thoreson, C. J. (2002). Are measures of self-esteem, neuroticism, locus of control, and generalized self-efficacy indicators of a common core construct? Journal of Personality \& Social Psychology, 83, 693-710.

Judge, T. A., Locke, E. A., \& Durham, C. C. (1997). The dispositional causes of job satisfaction: A core evaluations approach. Research in Organizational Behavior, 19, $151-188$.

Kanfer, R., \& Heggestad, E. D. (1997). Motivational traits and skills: A person-centered approach to work motivation. Research in Organizational Behavior, 19, 1-56.

Locke, E. A., McClear, K., \& Knight, D. (1996). Self-esteem and work. International Review of Industrial and Organizational Psychology, 11, 1-32.

Luszczynska, A., Scholz, U., \& Scwarzer, R. (2005). The general self-efficacy scale: Multicultural validation studies. The Journal of Psychology, 139, 439-457.

Revelle, W. (2014). psych: Procedures for personality and psychological research (R package version 1.4.1). Evanston, IL: Northwestern University.

Rothmann, S., \& Cilliers, F. V. N. (2007). Present challenges and some critical issues for research in industrial/organisational psychology. South African Journal of Industrial Psychology, 33, 8-17.

Scherbaum, C. A., Cohen-Charash, Y., \& Kern, M. J. (2006). Measuring general selfefficacy: A comparison of three measures using item response theory. Educational \& Psychological Measurement, 66, 1047-1063.

Scholz, U., Dona, B. G., Sud, S., \& Schwarzer, R. (2002). Is general self-efficacy a universal construct? Psychometric findings from 25 countries. European Journal of Psychological Assessment, 18, 242-251.

Sherer, M., Maddux, J. E., Mercandante, B., Prentice-Dunn, S., Jacobs, B., \& Rogers, R. W. (1982). The self-efficacy scale: Construction and validation. Psychological Reports, 51, 663-671.

Speier, C., \& Frese, M. (1997). Generalized self-efficacy as a mediator and moderator between control and complexity at work and personal initiative: A longitudinal field study in Germany. Human Performance, 1O, 171-192.

Van Prooijen, J., \& Van Der Kloot, W. A. (2001). Confirmatory factor analysis of exploratively obtained factor structures. Educational \& Psychological Measurement, $61,777-792$. 
Velicer, W. F. (1976). Determining the number of components from a matrix of partial correlations. Psychometrika, 41, 321-327.

Woodruff, S. L., \& Cashman, J. F. (1993). Task domain, and general self-efficacy: A reexamination of the self-efficacy scale. Psychological Reports, 72, 423-432. 